Superalloys 2012: 12 $^{\text {th }}$ International Symposium on Superalloys

\title{
MICROSTRUCTURE DEVELOPMENT DURING CONTROLLED DIRECTIONAL SOLIDIFICATION IN ALLOY 718
}

\author{
Ashish D. Patel, Jill Erbrick, Karl Heck, Gernant Maurer \\ Carpenter Technology Corp., 101 West Bern Street; Reading, PA, 19601, USA
}

Keywords: 718, Casting, Microstructure

\begin{abstract}
To better understand solidification in large ingot superalloy remelting processes, controlled directional solidification experiments were conducted to examine the effect of solidification time on microstructural evolution. Alloy 718 Cylinders, $25 \mathrm{~mm}$ in diameter, were directionally solidified at rates ranging from $0.75 \mathrm{~mm} / \mathrm{min}$ to $3 \mathrm{~mm} / \mathrm{min}$. Each casting was sectioned, characterized, and correlations were developed, relating the microstructural features to solidification time. Results indicate that in alloy 718 , as the solidification time increases, the dendrite arms spacing, Laves and carbide size also increases. The exponent of the solidification time correlation ranges from 0.4 to 0.55 , which is higher than earlier estimates. Developing a thorough experimental technique, and correlations between observed microstructural features and ingot casting parameters is key in generating solidification defect maps. This data is vital to Integrated Computational Materials Engineering (ICME) efforts in determining theoretical limits on processing parameter used during superalloy remelting using process models.
\end{abstract}

\section{Introduction}

Alloy 718 is the most widely used nickel-based superalloy and is currently used in numerous high performance applications. Typically, for these critical applications, the alloy is first vacuum induction melted (VIM) to get the appropriate bulk composition, followed by electroslag remelting (ESR) to remove inclusions and most importantly, provide a sound electrode for the final melting process, vacuum arc remelting (VAR). In each of these processes, the solidification conditions are different due to differences in the volume of the molten metal pool and the rate of heat extraction from the ingot being cast. The solidification times are high at the surface and considerably lower at the ingot center. This results in different micro and macro structure across the ingot cross-section.

The as-cast microstructure in alloy 718 consists of the primary gamma phase dendrites, carbides, Laves and delta phase [1]. The spacing and size distribution of these microstructural features largely depends on the local solidification conditions within the casting. The dendrite arm spacing is typically higher at the center of the ingot owing to the slower cooling conditions [2]. During the processing of alloy 718 , the cast ingot is subjected to intermediate heat treatment operations, and the heating time at temperature depends on the diffusion length scale, which is dictated by the microstructure.

Over the years, there have been attempts to model these casting processes, and macroscopic trends from the model appear to be consistent with real world observations. Also, results from VIM, ESR, \& VAR process models have been used to examine the effect of processing parameters on pool shape, flow \& temperature distribution during solidification. The next logical extension of these models is to predict likelihood of the formation of solidification related anomalies during the casting process. The inputs to any defect criteria relies on quantitative description of the microstructure, of which only limited data is currently available in the literature.

The purpose of this study was to systematically study the microstructural development in a small size casting solidified under conditions typical of much larger production size ingots of alloy 718 [3]. A controlled directional solidification furnace was used to cast $250 \mathrm{~mm}$ diameter cylinders using different withdrawal rates, which in turn resulted in different cooling rates \& solidification times. The resulting microstructures were thoroughly characterized, and the results were compared with similar data from an actual production size ingot. Generally speaking, in remelt processing, the mushy zone growth rate is inversely proportional to the square of the ingot diameter. Hence a higher speed is representative of smaller laboratory size ingots, and for larger diameter ingots, the quasi-steady growth rate is proportionately lower.

\section{Experimental Procedure}

The directional solidification furnace used in this study consisted of two sections, a VIM furnace to melt the charge, and a casting region. After melting the charge, the VIM furnace was tilted and the molten metal was poured into a pre-heated instrumented shell mold. After filling the mold, the entire casting was gradually withdrawn from the hot zone at a pre-determined rate, with the solid/liquid interface normal to the withdrawal direction.

In this study, small cylindrical pieces of alloy 718 (of nominal composition) $25 \mathrm{~mm}$ dia. and $203 \mathrm{~mm}$ long were cast using withdrawal rates of $0.75 \mathrm{~mm} / \mathrm{min}, 1.25 \mathrm{~mm} / \mathrm{min}, 2 \mathrm{~mm} / \mathrm{min}$ and 3 $\mathrm{mm} / \mathrm{min}$. The cylinders were then split in half longitudinally, and the microstructure analyzed in both the longitudinal and transverse directions as seen in Figure 1.

The pieces were polished and etched with a freshly prepared solution containing, $100 \mathrm{ml} \mathrm{H}_{2} \mathrm{O}, 100 \mathrm{ml} \mathrm{HCl}, 100 \mathrm{ml} \mathrm{HNO}_{3}$, and 3 grams molybdic acid. This etchant worked very well in delineating the cast microstructure. The samples were analyzed using standard optical microscopic techniques for measuring the primary dendrite arm spacing (PDAS) and secondary dendrite arm spacing (SDAS) at low magnification. In order to determine the SDAS, a line was placed along the length of approximately 10-15 secondary dendrite arms. The SDAS was then calculated by dividing the measured length of the line by the number of secondary arms intercepted. The primary dendrite arm spacing was determined by measuring the distance from one primary dendrite to another from the transverse sections. Approximately 20- 30 measurements were taken from the center to the mid-radius region of each sample. 
Next, higher magnification images were recorded and these images were imported into ImageJ Software for qualitative analysis of Laves phase and carbides. Microprobe measurements were also carried out to determine the extent of micro-segregation.

\section{Results}

The macrostructure in Figure 1 shows that grains at the center are nearly vertical, i.e., normal to the cross-section, the grains at the surface appear to diverge away from the center line. This indicates that the solidification interface is flat at the center and slightly convex at the edges. There was no evidence of macro-segregation in any of these castings.

The measured temperature distribution during the process is shown in Figure 2. The sampling rate was $1 \mathrm{~Hz}$, and the cooling rate was determined by taking the slope, using a moving array of 60 data points (1 minute average) using the following relationship:

$$
\dot{T}=\frac{\operatorname{Ave}(T \cdot t)-\operatorname{Ave}(T) \operatorname{Ave}(t)}{\operatorname{Ave}\left(t^{2}\right)-\operatorname{Ave}(t)^{2}}
$$

Where, $\mathrm{T}$ is the measured temperature, $\mathrm{t}$ is time, and $\dot{T}$ is the cooling rate. The cooling rates determined from Eq. 1 from thermocouples located 3, 4, 6, and 7 inches from the bottom were within $10 \%$ of each other.

Optical light microscopy results are shown in Figure 3. The data from these controlled directional solidification experiments are compared against that from a typical production size VAR ingot. The dot plots in Figure 3-A, 3-B show that both secondary and primary dendrite spacing of the gamma phase decrease with increasing withdrawal rate (faster cooling rate or lower solidification time).

The average secondary dendrite arm spacing (SDAS) ranges from $173 \mu \mathrm{m}$ at the lower withdrawal rate of $0.75 \mathrm{~mm} / \mathrm{min}$ to $65 \mu \mathrm{m}$ at $3 \mathrm{~mm} / \mathrm{min}$. The range of the SDAS data is $\pm 10 \%$ of the mean. The average primary dendrite arm spacing (PDAS) on the other hand varies from $257 \mu \mathrm{m}$ to $109 \mu \mathrm{m}$ under these test conditions, shows a larger scatter, $\pm 40 \%$ of the mean at each condition. The data gathered in this study is correlated to the solidification time the following relationship

$$
\begin{aligned}
& \operatorname{SDAS}(\mu \mathrm{m})=(1.46) T_{s}^{0.55} \\
& \operatorname{PDAS}(\mu \mathrm{m})=(5.83) T_{s}^{0.43}
\end{aligned}
$$

Where, $T_{s}$ is the solidification time in seconds, obtained by dividing the solidification interval by the average cooling rate obtained for each experimental condition.

The measurements of the secondary phase size, fraction and morphology are shown in Figures 3-C and 3-D. At lower withdrawal rate (lower cooling rate) the average Laves size is about $251 \mu \mathrm{m}^{2}$, and it decreases to nearly $98 \mu^{2}$ at the faster withdrawal rate, and is correlated to the solidification time by

$$
\operatorname{Laves}\left(\mu \mathrm{m}^{2}\right)=(3.07) T_{s}^{0.51}
$$

The carbides shown in Figure 3-D represent both the primary and eutectic carbides. Quantitative data for both laves phase and carbides is shown in the Table 1. The average carbide size and area fraction is higher at lower cooling rates. The maximum and average carbide size was found to correlate to the solidification time as follows,

$$
\begin{aligned}
& C_{\max }\left(\mu m^{2}\right)=2.036 T_{s}^{0.4} \\
& C_{a v e}\left(\mu m^{2}\right)=5.92 T_{s}^{0.2}
\end{aligned}
$$

It is interesting to note that the aspect ratio (which is the ratio of the larger to smaller dimension), of the carbides and Laves phase is not altered by using different withdrawal rates as seen in Table I. Laves phase has a higher aspect ratio, indicating that its more elongated compared to the carbides, which is consistent with observations made under the optical microscope.

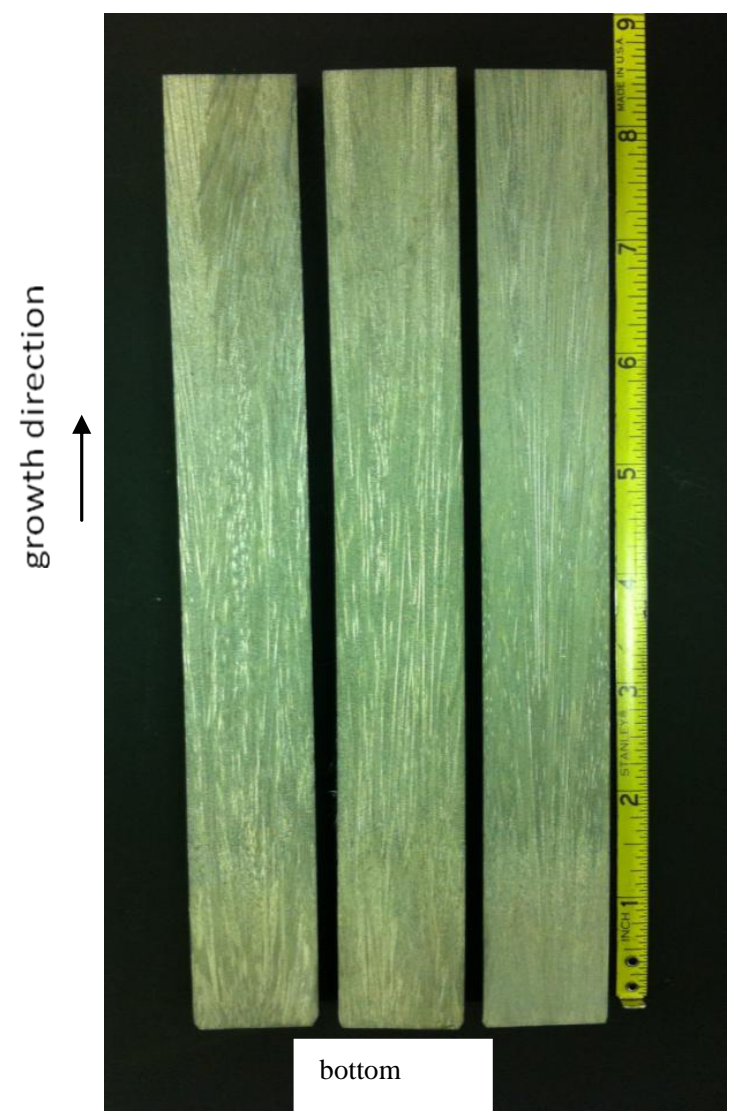

Figure 1: Directionally solidified ingot macrostructure for withdraw rates of $0.75,1.25$, and $3.0 \mathrm{~mm} / \mathrm{min}$. Ferric Chloride based etch used to reveal macrostructure. 
Figure 4 shows the SDAS and Laves phase evolution from the bottom of the casting. This data indicates the presence of a very fine microstructure at the very bottom, where the cooling rates are high. The initial transient region appears to be confined to the bottom $18 \mathrm{~mm}$ of the casting, and does not appear to vary much with withdrawal rate. Several sections were examined along the length of the casting, and microstructure did not vary significantly after $18 \mathrm{~mm}$ from the bottom. It appears that after about $18 \mathrm{~mm}$ from the bottom, the quasi-steady conditions are established.

Microprobe analysis was also conducted by taking line scans at different locations, at $5 \mu \mathrm{m}$ intervals along the primary dendrites. The partition ratios were calculated by determining the ratio of the minimum composition to the bulk composition $\left(\mathrm{k}=\mathrm{C}_{\min } / \mathrm{C}_{\mathrm{o}}\right)$. The data showed that niobium, titanium and molybdenum segregate to the inter-dendritic region, with the partition ratio less than unity $(\mathrm{k}<1)$. The partition ratios range from 0.45 to 0.55 for niobium, 0.65 to 0.7 for titanium and $0.75-0.8$ for molybdenum.
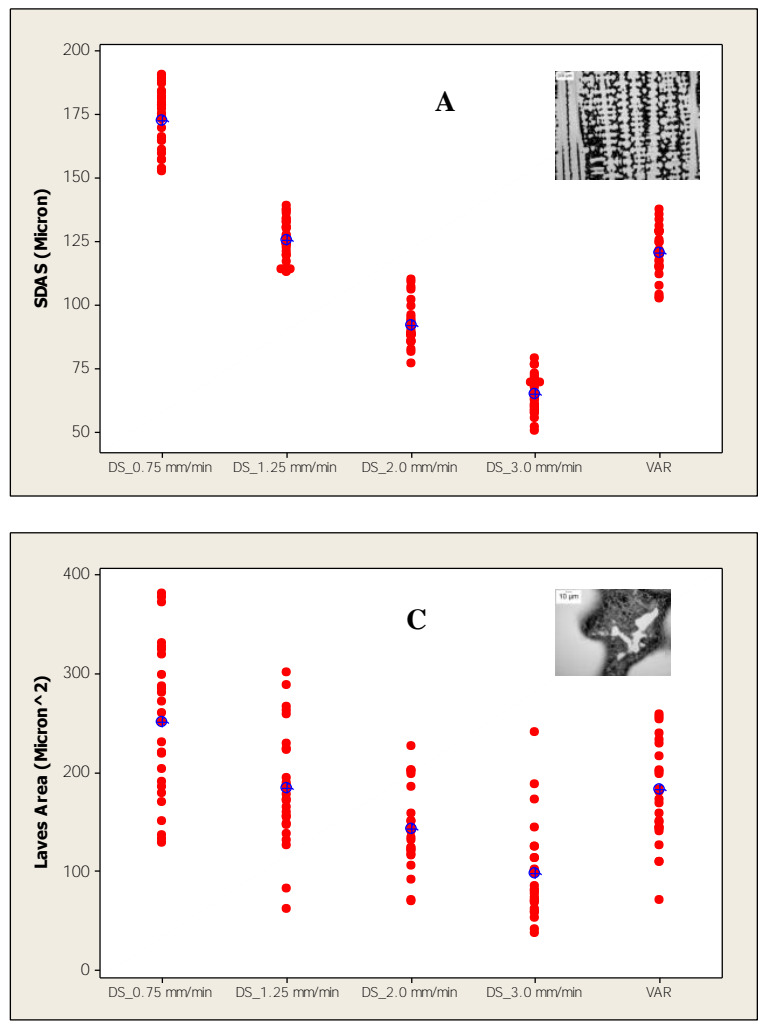

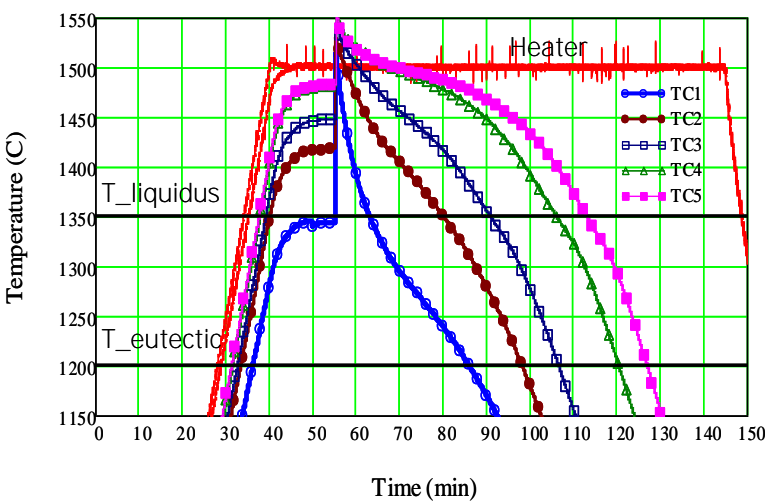

Figure 2: Measured temperature during the directional solidification process, withdrawal speed of $3 \mathrm{~mm} / \mathrm{min}$. The first thermocouple (TC1) was located $50 \mathrm{~mm}$ from the bottom (chill), followed by thermocouples at $75 \mathrm{~mm}, 100 \mathrm{~mm}, 150$ $\mathrm{mm}$, and $175 \mathrm{~mm}$ (TC5) from the bottom.
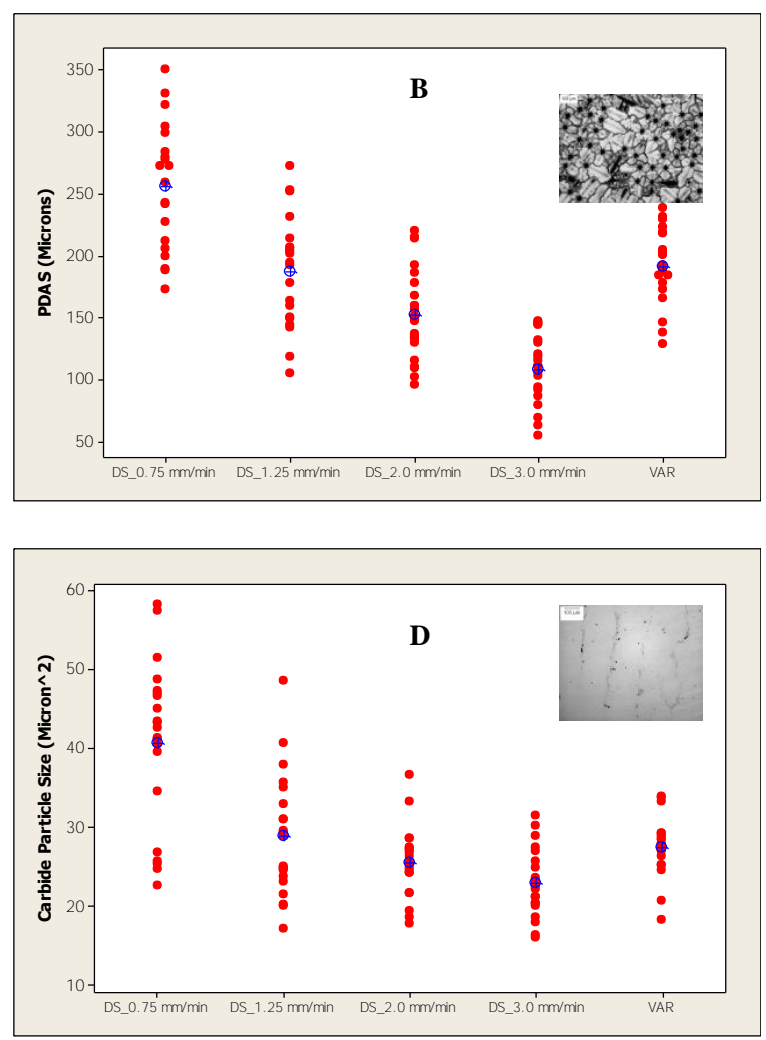

Figure 3: Quantitative metallographic analysis of the microstructure of directionally solidified alloy 718, cast at withdrawal rates of 0.75 , 1.25 , and $3 \mathrm{~mm} / \mathrm{min}$. (A) Measured secondary dendrite spacing using the intercept method from longitudinal sections, (B) Measured primary dendrite arm spacing from transverse sections, (C) Laves size, (D) Carbide size. 
Table I: The measured average size, phase fraction and morphology of Laves and carbides, (brackets) denote one standard deviation

\begin{tabular}{|c|c|c|c|c|c|c|}
\hline & \multicolumn{3}{|c|}{ Laves } & \multicolumn{3}{|c|}{ Carbides } \\
\hline Case & $\begin{array}{r}\text { Area } \\
\mu \mathrm{m}^{2}\end{array}$ & $\begin{array}{c}\text { Area Fraction } \\
\mu \mathrm{m}^{2} / \mathrm{mm}^{2}\end{array}$ & $\begin{array}{c}\text { Aspect Ratio } \\
\text { Dimension-less }\end{array}$ & $\begin{array}{l}\text { Area } \\
\mu \mathrm{m}^{2}\end{array}$ & $\begin{array}{c}\text { Area fraction } \\
\mu \mathrm{m}^{2} / \mathrm{mm}^{2}\end{array}$ & $\begin{array}{c}\text { Aspect Ratio } \\
\text { Dimension-less }\end{array}$ \\
\hline 0.75 & $251(78)$ & 7594 (2360) & $2.77(1.23)$ & $\begin{array}{c}38 \\
(37)\end{array}$ & $\begin{array}{c}51.17 \\
(13.19)\end{array}$ & $\begin{array}{c}1.64 \\
(0.66)\end{array}$ \\
\hline 1.25 & $185(59)$ & 5602 (1789) & $2.61(1.47)$ & $\begin{array}{c}27 \\
(31)\end{array}$ & $\begin{array}{l}36.94 \\
(9.86) \\
\end{array}$ & $\begin{array}{r}1.66 \\
(0.59) \\
\end{array}$ \\
\hline 2.0 & $143(41)$ & 4419 (1514) & $2.57(1.35)$ & $\begin{array}{l}25 \\
(23)\end{array}$ & $\begin{array}{l}32.54 \\
(5.67) \\
\end{array}$ & $\begin{array}{r}1.72 \\
(0.64) \\
\end{array}$ \\
\hline 3.0 & $98(47)$ & $2973(1429)$ & 2.55 (1.32) & $\begin{array}{c}24 \\
(28)\end{array}$ & $\begin{array}{l}33.41 \\
(8.16)\end{array}$ & $\begin{array}{c}1.75 \\
(0.69)\end{array}$ \\
\hline VAR & $183(57)$ & 5003 (2087) & $2.70(1.04)$ & $\begin{array}{c}28 \\
(28) \\
\end{array}$ & $\begin{array}{l}35.09 \\
(4.71) \\
\end{array}$ & $\begin{array}{r}1.75 \\
(0.73) \\
\end{array}$ \\
\hline
\end{tabular}

-

$100 \mu \mathrm{m}$

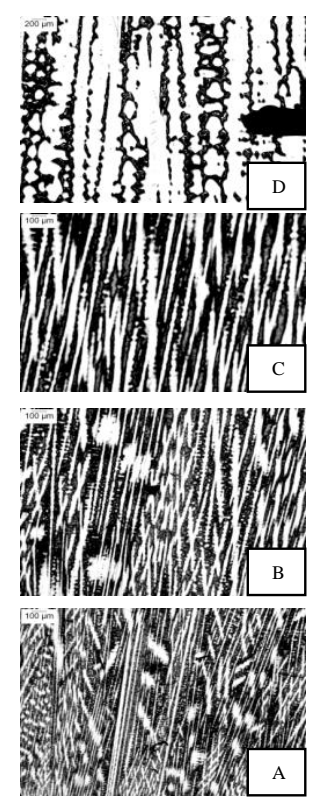

Bottom

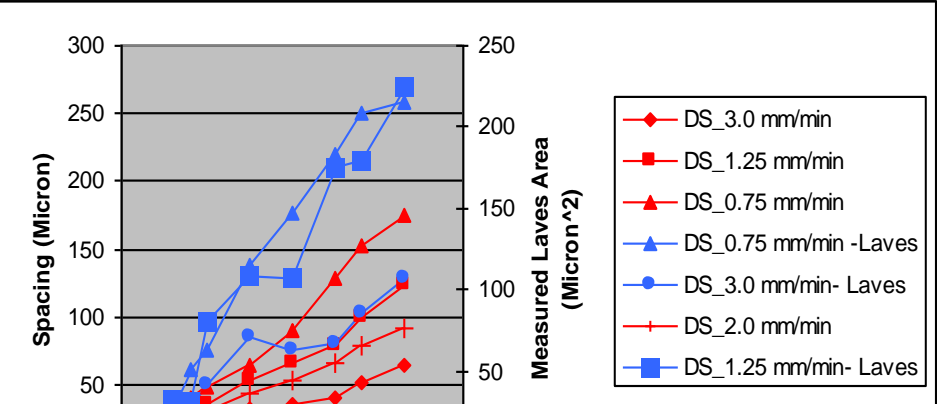

$\overline{10} \mu \mathrm{m}$
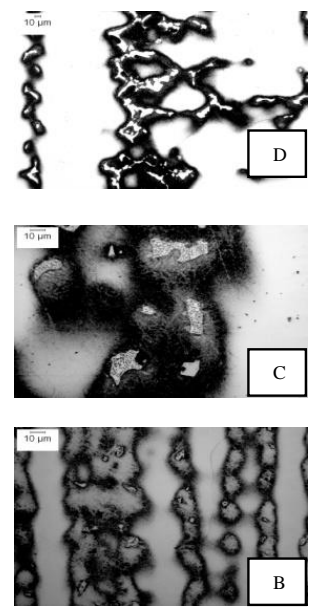

Distance From Bottom of Casting

$(\mathrm{mm})$

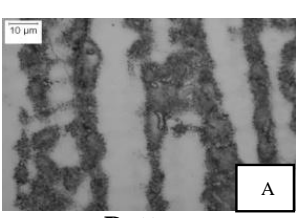

Bottom

Figure 4: Quantitative metallographic analysis of the microstructure of directionally solidified alloy 718, cast at withdrawal rates of $0.75,1.25$, and $3.0 \mathrm{~mm} / \mathrm{min}$. The data series show the distance from bottom of casting versus the measured SDAS and measured Laves area at various withdraw rates. Micrographs showing the evolution of the secondary dendrites (left) and laves phase (right) are also shown. Each of these micrographs shown here represents the typical structure within a $5 \mathrm{~mm}$ vertical region. Micrograph (A) is representative of the region $0-5 \mathrm{~mm}$ from the bottom, (B) is typical of 5-10 mm from the bottom, (C) is $10-15 \mathrm{~mm}$ from the bottom and (D) is $15-20 \mathrm{~mm}$ from the bottom of the casting. 


\section{Concluding Comments}

An experimental technique to study the effect of withdrawal rate on microstructural development during directional solidification is presented. The solidification time is correlated to the microstructural features of as-cast alloy 718 . In all cases, the exponent of the solidification time is greater than one third, which is typically considered as the nominal value for such correlations. These relationships are very valuable in predicting the likelihood of defects in VAR and ESR using the Rayleigh number based criteria, which relies on the both the secondary and primary dendrite arm spacing to determine the permeability in the mushy zone [4].

These days, process models for VIM, ESR and VAR are mature enough to predict trends during ingot solidification. Typical results from such a process model are shown in Figure 5 [6]. The radial and axial distances are normalized with respect to the radius of the ingot. In this particular case, using nominal processing

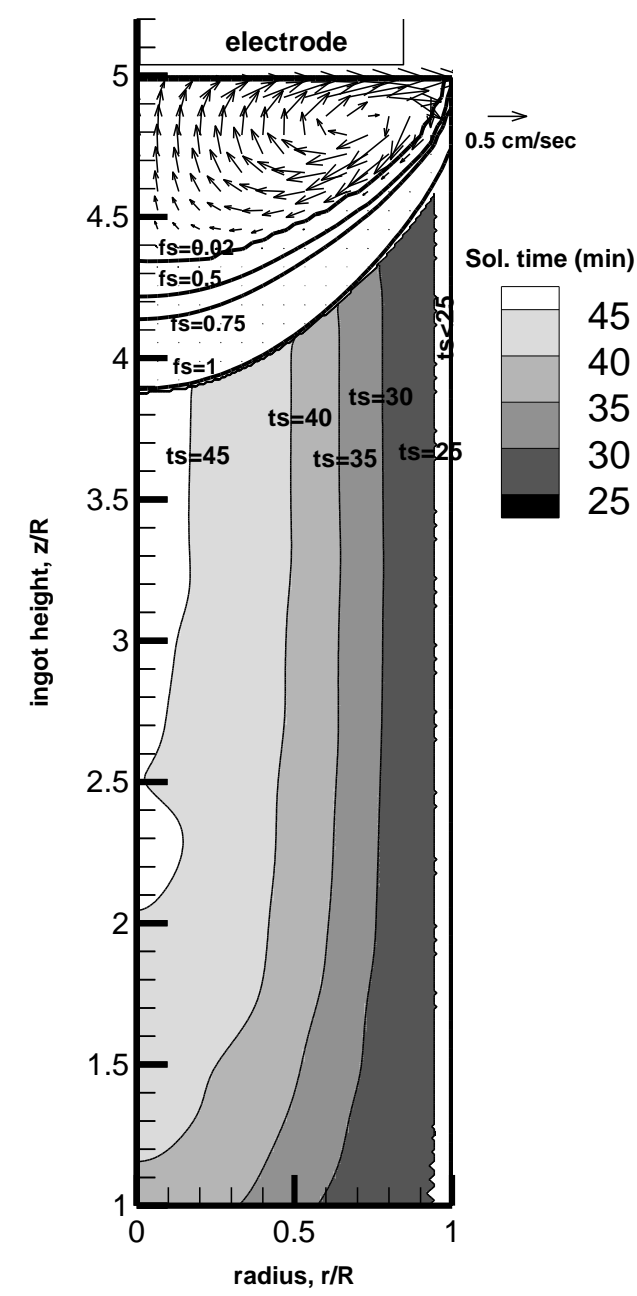

Figure 5: Computed solidification time, ts, in a VAR ingot. Also, shown is the buoyancy driven flow in the molten pool, and solid fraction, fs evolution in the mushy zone. parameters, the pool depth at the center is about 0.65 times the ingot radius, the flow is buoyancy driven, with a maximum velocity of $0.5 \mathrm{~cm} / \mathrm{sec}$. The solidification time at the ingot center is about $50 \mathrm{~min}$, and is less than $25 \mathrm{~min}$ close to the surface. Using Eq.2, the secondary dendrite arm spacing would range from 123 to $98 \mu \mathrm{m}$ at the ingot center.

Using a similar approach, the expected range of solidification times during processing of alloy 718 are shown in Figure 6, they vary from $10 \mathrm{~min}$ to $130 \mathrm{~min}$ for VAR and are slightly higher for ESR and range from $10 \mathrm{~min}$ and $200 \mathrm{~min}$, depending on ingot diameter and actual processing parameters. Equations 2 to 5 can now be used to readily predict the average size of the cast microstructural features as shown in Figure 7.

A simple heat transfer analysis indicates that the solidification time in water cooled molds would be proportional to the square of the ingot radius $\left(t_{s} \propto R^{2}\right)$ [7], and using equations 2-4, the micostructural features would then increase nearly linearly with ingot radius. Knowledge of such functional dependence is useful in designing optimum heat treatment cycles during process development \& improvement efforts.

Finally, in this study, since the withdrawal direction was normal to the solid-liquid interface no macro-segregation was observed, even at lower casting rates.

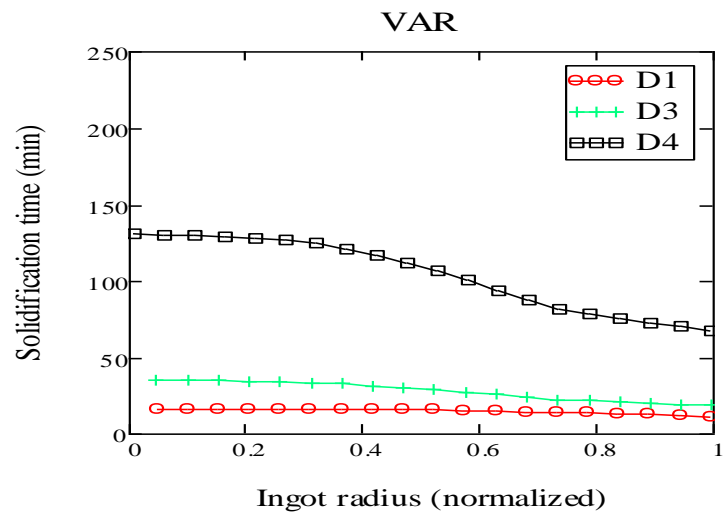

ESR

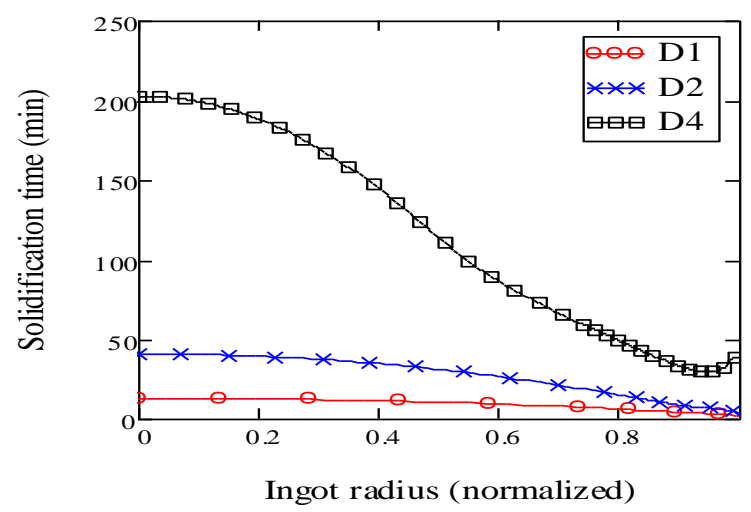

Figure 6: Computed solidification time in ESR and VAR using nominal processing parameters for each case. D1 $<$ D $2<$ D $3<D 4$ Data generated using process models described elsewhere $[6,8]$. 


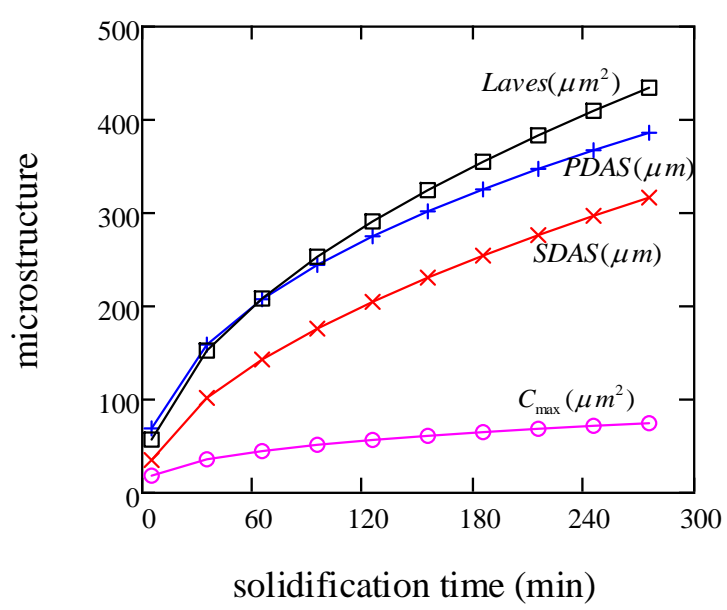

Figure 7: Effect of solidification time on the cast microstructure in alloy 718 .

\section{Acknowledgement}

The authors would like to thank Simon Hollad for conducting the DS trials at the Casting Institute, RWTH Aachen University.

\section{References}

[1] G. A. Knorovsky, M. J. Cieslak, T. J. Headley, A. D. Romig, W. F. Hammetter, "INCONEL 718: A Solidification Diagram", Met. Trans. A, Vol 20A, 1989, pp. 2149-2158.

[2] A.D. Patel and Y.V. Murty, "Effect of Cooling Rate on Microstructural Development in Alloy 718", Superalloys 718, 625, 706 and Derivatives, Ed. E. A. Loria, TMS (2001) pp. 123-132.

[3] Wan-Hong, J. J. deBarbadillo, K. Morita, T. Suzuki, W. Chen, K. Chang, "A Freckle Criterion for the solidification of Superalloys with a Tilted Solidification Front", JOM Sept 2004, pp 56-61.

[4] P. Auburtin, T. Wang, S. L. Cockcroft, and A. Mitchell, "Freckle Formation and Freckle Criterion in Superalloy Castings", Met. Trans B, Vol 31B, 2000, pp 801-811.

[5] J. A. Dantzig and M. Rappaz, Solidification, EPEL Press, 2009 .

[6] A. D. Patel, R. S. Minisandram, and D. G. Evans, "Modeling of Vacuum Arc Remelting of Alloy 718 Ingots", Ed: E. A. Green et.al, Superalloys 2004, TMS, pp. 917-924.

[7] D. R. Gaskell, An Introduction to Transport Phenomena in Materials Engineering, Macmillan, 1992.

[8] A. D. Patel, M. Gierula, and D. Tallman, "Bounds on Model
Parameters for Computational Analysis of the ESR Process", Intl. Symp. on Liquid Metal Processing and Casting, Ed. P. D. Lee et.al. 2009, pp. 2001-212. 